\title{
Developing Argumentation Skills among Undergraduate Students Using Inquiry Led Argument Framework
}

\author{
Fayyaz Ahmad Faize* \\ Muhammad Arshad Dahar ${ }^{* *}$
}

\begin{abstract}
Teaching of science subjects in developing countries is still geared around traditional methods. This study aimed at teaching science students through scientific argumentation as a newer method for teacher instructors and students in Pakistan. The objectives were to develop argumentation skills in science students using Inquiry Led Argument Framework (ILAF), to explore the effectiveness of the new framework and to assess the quality of arguments generated by students using ILAF. The sample consists of two sections of bio-ethic course in a large publicsector university serving as experimental and control group. Before introducing ILAF in the experimental group, it was carefully designed, validated and pilot tested with the students. The progression in argumentation skill was monitored through written argumentation reports collected during the semester while, the effectiveness of ILAF was found through comparing the students' academic performance with a control group at the end of semester. ILAF was found effective in developing argumentation skills and improving students' academic performance as compared to students in the control group. The students' quality of argument improved with practice. ILAF as a newer approach has the capacity to serve as a useful framework for teacher educators and science teachers in developing argumentation skills in students besides improving their academic performance.
\end{abstract}

Keywords: Argumentation; cooperative learning, inquiry, science education, performance

\footnotetext{
*Assistant Professor, Humanities Department, COMSATS Institute of Information Technology, Islamabad-Pakistan drfayyaz@comsats.edu.pk, fayyazaf@yahoo.com,

***Assistant Professor, PMAS Arid agriculture university. drarshad1969@uaar.edu.pk
} 


\section{Introduction}

Argumentation in science education is considered to be a core practice that can empower students develop their reasoning skills, criteria for knowledge evaluation, attain scientific literacy and other subsidiary skills (Berland \& Reiser, 2009; Erduran, Ozdem, \& Park, 2015; JiménezAleixandre \& Erduran, 2008; Kelly, Druker, \& Chen, 1998). Teaching of science subjects in developing countries is still focused on traditional methods with limited opportunities for learning experiences (Faize, Dahar, \& Niwaz, 2010). In Pakistan, the most frequently used method with students of higher education is the lecture method (Faize, 2011) which is rated as the best instructional method by university students (Sajjad, 2010). However, there is no single teaching method, which may be effective in all situations due to the different learning needs of students (Umer \& Siddiqui, 2013). Argumentation in teaching socioscientific topics has gained the attention of researchers during the last few decades. However, there is little research on teaching students through argumentation in Pakistan (Faize, 2015). Indeed, students lack argumentation skills at all levels and there is no serious effort to address this problem (Lu \& Zhang, 2013). The principal goal of this study is to involve students in argumentation on socio-scientific issues (SSI) in a public-sector university in Pakistan. The course of 'Introduction to Bioethic' was selected as covering most of SSI. The benefit of selecting SSI is that it provides students the opportunity to actively reflect their views and indulge in argumentation with valid justifications (Chang and Chiu 2008).

The research would focus on development and testing of an approach to incorporate scientific argumentation in teaching, to evaluate the effectiveness of this approach in improving argumentation skills, and to explore its effect on students'academic performance at the end of the course.

\section{Argumentation and its Components}

Argumentation is a discursive and dynamic process in which a claim is made and supported to convince others and critiquing the alternatives (Osborne \& Patterson, 2011). Argumentation is derived from the work of Toulmin (1958), the twentieth century psychologist (Toulmin, 1958). He mentioned six components of a good argumentation: claim, data, warrant, backing, qualifier and rebuttal. 
- Claim: A statement identifying a decision.

- Data: Information for supporting the claim.

- Warrant: The link between the data and the claim.

- Backing: To support warrant.

- Qualifier: The intensity of being confident in making a claim and supporting an argument.

- Rebuttal or refutation: It sets the condition under which a person may revise one's claim and to offer counter argument.

Toulmin (1958) illustrated these components through the following example.

The issue relates to a boy named Harry and whether Harry is a British subject. The claim is that Harry is a British subject, because Harry was born in Bermuda (Data). A person born in Bermuda is generally a British subject (warrant). Due to legal provisions and laws (Backing), most probably, he is a British subject (qualifier); however, he will not be a British subject if he becomes a naturalized American or both his parents were aliens (rebuttal).

\section{Benefits of Teaching through Argumentation}

The use of argumentation in science education is found to improve conceptual understanding (Kaya, 2013; Osborne, Christodoulou, HowellRichardson, \& Richardson, 2013). It involves making a decision and supporting it with evidences. This is challenged by the opponent through counter arguments. The students think of other alternatives to support their argument and provide further clarifications, elaborations and evidence. This helps both the sides know each other viewpoints leading to more conceptual understanding (Newton, Driver, \& Osborne, 1999). Argumentation helps in developing critical skills (Kaya, 2013) assisting students in making informed decisions (van Gelder, Bissett, \& Cumming, 2004) and even changes students' attitude towards science (Hong, Lin, Wang, Chen, \& Yang, 2013).

\section{Present Study}

The use of argumentation in teaching science is an effective method as already discussed. It is important that educational institutions should provide ample opportunities to its students to learn and practice with argumentation (Kaya, 2013; Shirley Simon, Erduran, \& Osborne, 2006). One problem that we faced was that the instructors were mostly familiar with the lecture method and thus, have little experience of using 
argumentation during teaching. This was also observed by Yesiloglu (2007). The present research thus aimed at introducing argumentation in teaching university courses in Pakistan, to design a working framework for developing argumentation skills in students and to explore its effect on students' academic performance.

\section{Objectives of the Study}

The objectives of the study were to:

1. Develop an approach for incorporating scientific argumentation in science teaching

2. Evaluate the quality of students' written argumentation skills at various point of time during the semester

3. Measure the effect of argumentation approach on students' academic performance at the end of course

Overall, the study asked:

i. Can an argumentation strategy be developed successfully?

ii. How do learners react to the approach?

iii. What are the performance effects of the strategy?

It was assumed that the students had never experienced argumentation approach in previous learning situations. It was, therefore, necessary to give them some background training in what was involved. This is now described.

\section{Theoretical Framework}

The present study is guided by constructivists learning theory. Constructivism refers to conditions that knowledge is acquired through a process of active construction (Mascolo \& Fischer, 2004). The theory derived its strength from the work of Dewey (Dewey, 1938), Piaget (Piaget, 1964) and Vygotsky (Vygotsky \& Cambridge, 1978). Dewey stressed that students should be provided opportunities so that they can think and use their sensory inputs to arrive at new knowledge themselves. This learning can be constructed individually (Piaget, 1964) or through a process of social interaction (Vygotsky, 1978). Students learn better through interaction with their peers, teachers, family members and environment and not in isolation. The present study used this framework and provided environment to students individually as 
well as in groups to construct new information and then sharing this with other groups in an interactive atmosphere.

\section{Methodology}

\section{Sample}

The sample consists of students of Bio-ethic course in a large higher education institute in Islamabad. The number of students registered for the course 80 divided into two sections. One section was comprised of 48 students with 36 females and 12 male students and served as experimental group. The second section comprised of 32 students having 24 females and 8 male students that also served as control group. The two groups were equivalent based on university's classification of forming sections based on marks in intermediate examination (grade 12). The effect of intervention was observed through simple experimental design as given below:

Experimental group $\rightarrow$ Treatment $\rightarrow$ Observation $\mathrm{O}_{1}$

Control group $\rightarrow$ Observation $\mathrm{O}_{2}$

\section{Training Sessions}

The researchers designed a nine-step framework to help in conducting argumentation with the students. This was named Inquiry Led Argument Framework (ILAF). The researchers conducted two training sessions about ILAFeach of one-and-half-hour duration with the students of experimental group and the course instructor. Relevant examples were given to clarify ILAF. The detail of ILAF is given in the 'steps in ILAF'. In the second week, the course instructor and the researchers introduced ILAF in the class. The researchers ensured his presence during the class reserved for argumentation to provide necessary feedback. The students were asked to write their argument on argumentation backup form (Appendix A) prepared specifically for the purpose. Ten classes were reserved for teaching through ILAF during the semester with each class of one-and half hour duration. 


\section{Addressing the Research Aims}

The following procedure was followed to achieve the objectives.

\section{Table 1}

The Approach Adopted

\begin{tabular}{|c|c|c|}
\hline Objective & Question & Approach \\
\hline $\begin{array}{l}\text { Develop an approach for } \\
\text { incorporating scientific } \\
\text { argumentation in teaching bio- } \\
\text { ethics course }\end{array}$ & $\begin{array}{l}\text { Can it be done } \\
\text { and, if so, how? }\end{array}$ & $\begin{array}{l}\text { Related literature and consultation } \\
\text { was employed to develop a } \\
\text { procedure named as Inquiry Led } \\
\text { Argument Approach (ILAA) for } \\
\text { teaching bio-ethics course. After } \\
\text { review by five 'experts', it was } \\
\text { pilot tested in an undergraduate } \\
\text { bio-ethic course and data were } \\
\text { collected for three classes, leading } \\
\text { to minor adjustments. }\end{array}$ \\
\hline $\begin{array}{l}\text { Explore the quality of students' } \\
\text { written argumentation skills at } \\
\text { various times during the } \\
\text { semester }\end{array}$ & $\begin{array}{l}\text { Did their } \\
\text { argumentation } \\
\text { skills develop } \\
\text { with time and } \\
\text { experience? }\end{array}$ & $\begin{array}{l}\text { Written argumentation reports } \\
\text { were collected during the semester } \\
\text { for } 10 \text { topics. The quality of } \\
\text { argumentation was analyzed using } \\
\text { GC-AP framework and changes in } \\
\text { the development of the skill } \\
\text { analyzed using ANOVA repeated } \\
\text { measure design for three stages: } \\
\text { start, middle, end. }\end{array}$ \\
\hline $\begin{array}{l}\text { Evaluate the effectiveness of } \\
\text { argumentation approach in } \\
\text { improving students' academic } \\
\text { performance }\end{array}$ & $\begin{array}{l}\text { Did the } \\
\text { argumentation } \\
\text { approach make } \\
\text { any difference to } \\
\text { final } \\
\text { performance? }\end{array}$ & $\begin{array}{l}\text { The performance of the } \\
\text { experimental group was compared } \\
\text { with students in the control group } \\
\text { (carefully matched but taught } \\
\text { using lecture approach by the same } \\
\text { teacher) using a 't' test. }\end{array}$ \\
\hline
\end{tabular}

\section{Research Instrument}

The data for the present study was collected through:

1. Argumentation backup form filled by students during ILAF sessions

2. Open ended questionnaire to be filled by students at the end of semester

The students were distributed an outline in the first week that mentioned the name of the topic and the date for conducting 
argumentation session. The students were encouraged to read critically about the topic in advance before argumentation session was conducted. The number of written argumentation reports ranged between 42 and 48 for each session resulting in more than 400 written argumentation reports. For coding and analyzing argumentation reports in more detail, the researchers selected reports for three argumentation sessions that include reports during the start of the semester, mid of semester and end of semester. The topics for writing argumentation reports were medically assisted death, abortion and, animal rights and experimentation. The total number of argumentation reports that were coded and analyzed for the three sessions were 140 .

\section{Steps in Inquiry Led Argument Framework}

For introducing scientific argumentation, the researchers designed a procedure named as Inquiry Led Argument Framework (ILAF). The researchers took guidance from 'Argument Driven Inquiry' (ADI) model presented by Sampson, Grooms, and Walker(Sampson, Grooms, \& Walker, 2011) and, Walker and Sampson (Walker \& Sampson, 2013) in designing ILAF. However, ADI model consists of seven steps and was focused on laboratory instruction while ILAF is focused on scaffolding argumentation in actual classroom setting. ILAF was a modified version of ADI.

There were nine steps in ILAF which was validated by three experts and then pilot tested with a group of students before its use in this study. The inter-rater reliability was calculated using Cohen's kappa with value of $\kappa=.81$ which was satisfactory.

ILAF includes nine steps, which are as follows:

1. Sequencing the topic. The teacher distributes the course outline at the start of the semester. The topics appropriate for argumentation are highlighted in the course outline such as organ donation, organ transplantation, cloning, family planning, selective abortion, doctors aiding in death, destroying human embryo for research, abortion of an embryo with impairment etc. The teacher seeks students' opinion on sequencing these topics for learning purposes. Based on the majority decision, the topics are sequenced week-wise.

2. Group formation. The teacher makes groups with 4 to 5 students in each group. The students are given choice to change their groups in ensuing classes if they are not comfortable.

3. Introducing the topic: The teacher announces the topic for argumentation at the start of the class. The specific issue on which argumentation is to be conducted is written on the white board. 
4. Conduct of inquiry by students. The students are given time to think about the topic, make a tentative decision and then involve in the collection of data. The students work in a cooperative learning environment with individual as well as group accountability. The students collect data through mutual discussion, reading textbook or searching on internet. The students are allowed to use laptops, smart phones, tabs etc. This inquiry driven process is very necessary as without background information, it is difficult to construct an argument (Koslowski, 1996). The ICT supported devices are allowed for 5 to 10 minutes to prevent diversion from the topic.

5. Construction of argument. The students construct argument and then write it on a paper. Such practices enable the students to assess their ideas and consolidate their learning through repeated practices (Sampson \& Walker, 2012). In order to support students in writing quality arguments, an argument backup form is given to students for each topic (Appendix A). This form is a modified and improved version of the structure suggested by Nussbaum (Nussbaum, 2002) and is designed by the researchers for this study.

6. Legitimization of disparate ideas and consensus. If students in a group share the same views, then the position of the group is determined and legitimization is not needed. When students in a group have diverse views, then the group members are asked to discuss mutually the disparate ideas and arrive at consensus. Legitimization phase is very important during argumentation session. The process helps in abandoning unwanted and fallacious ideas and bring consensus within the group.

7. Collection of written argumentation report. The written argumentation reports are collected by teacher to avoid any change or modification by students. The purpose is to analyze the quality of argumentation and its progression throughout the semester.

8. Conduct of argumentation session. This is the most interactive stage in which the groups present their argumentation reports before the class. Some groups share the same decision/claim however; they differ in providing elaborations and rebuttals. The arguments presented by the groups are noted by two students on the white board for discussion and feedback purposes. It also helps the students in taking notes from the white board for learning purposes.

9. Conclusion of the session. After the interactive session of argumentation, the students learn a range of ideas and different perspectives of the topic. The teacher concludes the topic to provide direction towards desired learning and summarize the whole class session with due appreciation to groups participation and contribution. 


\section{Analysis of Data}

The written argumentation backup forms filled by students were carefully examined and analyzed using Grounds Competency Argument Pattern (GC-AP) mentioned by Foong and Daniel (2013). GC-AP provides a simpler way of analyzing quality of an argument by considering a few components: claim, grounds and rebuttal. For making analysis simpler with reference to components, the grounds were further divided into poor grounds and rich grounds. A poor ground consisted of one example or elaboration while, a rich ground included more than one example or elaboration to support the claim. The argumentation pattern was categorized into five patterns. Pattern 1 was the lowest and pattern 5 the highest with respect to quality. Each pattern was assigned a score based on its quality (Table 2). Score was given whether in favour or against the SSI if backed by correct content knowledge or scientifically correct.

Table 2

Argumentation pattern and components

\begin{tabular}{ccc}
\hline Argument Component & Argumentation Pattern & Score Assigned \\
\hline Claim/decision only & 1 & 1 \\
Claim, poor ground, no refutation & 2 & 2 \\
Claim, rich grounds, no refutation & 3 & 3 \\
Claim, poor ground, refutation added & 4 & 4 \\
Claim, rich grounds, refutation added & 5 & 5 \\
\hline
\end{tabular}

Refutation or rebuttal was the most significant indicator of a quality argument and was assigned the highest score. The reason for this is that rebuttal is most difficult to construct in argumentation and reflects higher order thinking skills (Christenson \& Chang, 2015; Toulmin, 1958). The semester duration was 16 weeks. The total number of students in the experimental group was 48 and it was not possible to scrutinize the Written Argumentation Reports (WAR) of all students for all weeks. Thus, the researchers analyzed the WAR for three stages; week 2, week 8 and week 15 to evaluate the progression in students' argumentation skills. These stages corresponded to the start of the semester, middle and the end of semester. The score obtained by each student on WAR during the stage was noted and the class mean was found for each stage. The performance of the class for the three stages was compared using repeated measure 
ANOVA through SPSS PASW 18 (reg.). The test was used to compare performance of the same sample during the three stages.

Furthermore, to observe the effectiveness of ILAF in improving students' performance, the score obtained by the experimental group in the semester examination was compared with students' score in a control group. The control group was taught by the same instructor using traditional lecture method. The semester examination included both objective and subjective test items. The performance of the two groups was compared using ' $\mathrm{t}$ ' test.

The last instrument was an open-ended questionnaire designed to seek students' views about ILAF. The students' responses were tabulated for similar themes and based on their frequency were converted into percentages.

\section{Examples of Argumentation Patterns}

The following example is chosen from one session of ILAF to understand argumentation pattern. The topic/issue given to the class was:

Patients with acute diseases and painful suffering. Will you allow doctors aiding such patients in death?

Pseudonyms are used instead of actual names.

[Rahim]: I will never allow a doctor helping such a patient to death (claim). Human life is sacred and in no way it can be taken like this (weak ground). [Pattern 2]

[Gul]: Yes (claim), if patients' disease is incurable, then they have the right to end their life (ground). Because prolong suffering may be painful for the patients and their family (further elaboration). [Pattern 3]

[Fazal]: Not allowed (claim). It is against law and our religion (ground). The doctor's duty is to save life and not to take it (further elaboration). If a patient is surviving on machine support and is in acute pain with no chance of living, then it may be allowed with the consent of patient as well as the patients' family (refutation/rebuttal). [Pattern 5]

\section{Results and Discussion}

The score assigned to each argumentation pattern was used to find the total score obtained by each student on his/her WAR. From table 2, the maximum score a student can get is 5 . The class mean was calculated by adding the score of all students on WARand then dividing by the number of students. The class mean was found for the three stages: beginning, middle and end (Table 3). The mean during the start of the 
semester was 2.40 , which increased to 3.11 after six weeks practice and the final mean score was 3.72 in the fifteenth week. The increase in the class means indicated an improvement in the students' performance with respect to quality of argument.

Table 3

Descriptive statistics for the three stages in experimental group

\begin{tabular}{llll}
\hline & Week 2 & Week 8 & Week 15 \\
\hline Valid sample & 48 & 46 & 46 \\
Missing from sample & 0 & 2 & 2 \\
Mean & 2.40 & 3.11 & 3.72 \\
\hline
\end{tabular}

The intervention was effective; however, more statistical tests were required to find if the difference was significant. The researchers applied ANOVA with repeated measure design on the data for the three stages and the value of ' $F$ ' was calculated. The results indicated that there were significant differences in the quality of argumentation for the three stages, $\mathrm{F}(2,42)=117.9, \mathrm{p}<.001, \eta^{2}=.849$. The value of eta squared was .849 , which was very high indicating large effect size due to ILAF.

In order to find which of the three stages have accounted for significant difference, a pair wise comparison of the three stages was performed (Table 4).

Table 4

Pairwise comparisons of the three stages

\begin{tabular}{llll}
\hline$(\mathrm{I})$ & $(\mathrm{J})$ & Mean Difference $(\mathrm{I}-\mathrm{J})$ & Significance \\
\hline Stage 1 & Stage 2 & -0.66 & $<0.001$ \\
Stage 1 & Stage 3 & -1.27 & $<0.001$ \\
Stage 2 & Stage 3 & -0.61 & $<0.001$ \\
\hline
\end{tabular}

Stage 1 refers to start of semester, stage 2 refers to middle and stage 3 refers to the end of semester. The mean difference between stage 1 and 2 and between stage 1 and 3 was negative which was also significant at 
0.001. The difference between means of stage 2 and 3 was also negative and significant at 0.001 .

The means were higher in the later stages and thus accounted for negative difference. The students performed better at later stages with higher means. Thus, ILAF was effective in improving the quality of argument using inquiry process and through working in small groups (Hong et al., 2013). Osborne et al. also found improvement in students' academic performance with time; however, their results were not significant (Erduran, Simon, \& Osborne, 2004). The present study found a significant difference in students' performance with time showing effectiveness of ILAF. This improvement might also be ascribed to argumentation backup forms that helped the students in filling the required spaces leading to quality argument (Nussbaum, 2002).

The reason for progression in the quality of argument might also be ascribed to practice. This was suggested in other research studies as well concluding that argumentation is a skill which can be taught and improved with practice (Erduran et al., 2004; Sampson \& Walker, 2012). In order to find the effectiveness of ILAF, the scores obtained by students in the experimental group was compared with students in the control group in the semester exam and were analyzed using ' $t$ ' test on SPSS PASW 18 (reg.). The semester examination paper was alike for both the groups. The course instructor marked the papers with a predefined marking key, to avoid any bias. The results of ' $t$ ' test indicated a significant difference between the performance of students in the experimental and control group, $\mathrm{t}(78)=4.18, \mathrm{p}<0.001$.

ILAF helped in improving students' performance in the semester examination by writing superior answers (Nussbaum, 2011). As the teacher shifted from traditional teaching to a more interactive form of engagements, the students learnt the skills of investigating ideas and finding support to back their ideas. Similar findings are reported by Martin \& Hand (2009); and Iordanou (2013). Similarly, the students in experimental group exhibited greater understanding of the course content. Newton et al. (1999) and Sampson \& Clark (2008) also found improvement in students' understanding when taught through scientific argumentation. Students' understanding can be observed through their answers supported through reasoning, epistemological understanding and valid justifications (Walker and Sampson, 2013). The practice with writing argumentation developed students' ability for high order thinking and quality answers (Nussbaum, 2011; Osborne et al., 2013). Argumentation helped in improving students' concept, resulting in better performance as compared to control group (Aydeniz, Pabuccu, Cetin, and Kaya, 2012; Kaya, 2013). 
The views of students related to the use of ILAF is illustrated in figure 1.

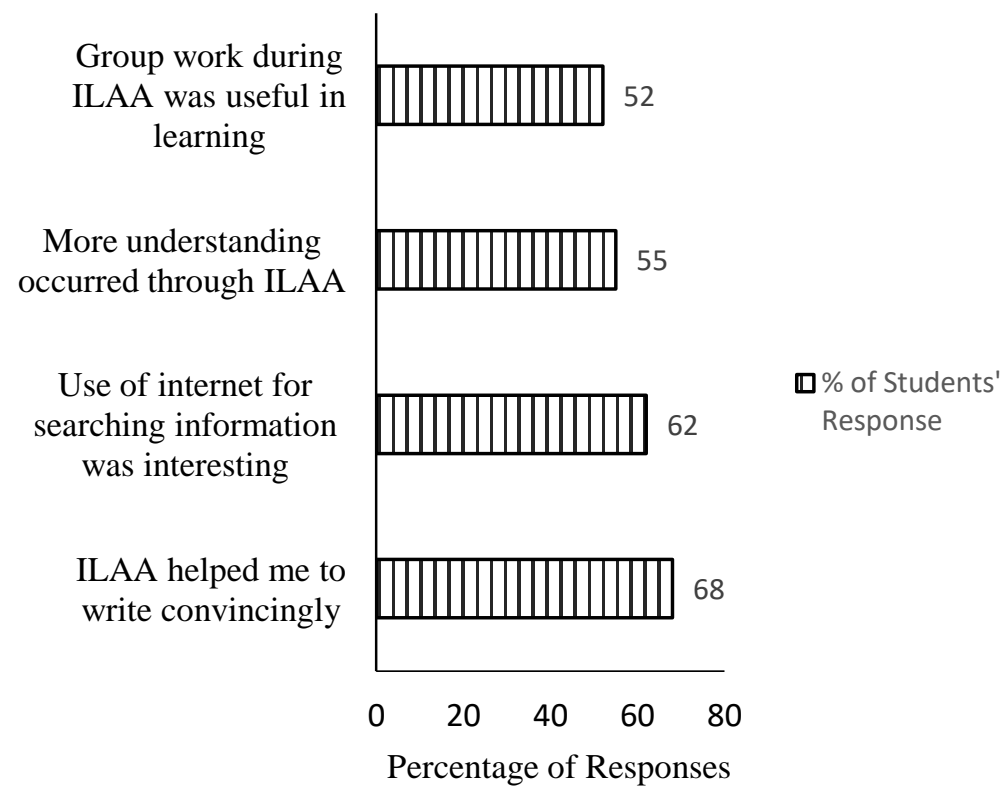

Figure 1: Students' views about ILAF

The students claimed that they learnt the skill of constructing valid arguments. They learnt how to convince others through valid grounds, clear examples and rational evidences. The students felt that the use of Internet for searching information was very helpful and interesting. The reason was that the students were not normally allowed to use Internet during their classes. However, they seemed enthusiastic when they used the Internet during class and also helped each other in recommending various information-based websites. The students stated that they understood the topics well through ILAF. Practice with ILAF motivated students and improved their understanding (von Aufschnaiter, Erduran, Osborne, \& Simon, 2008). They also expressed that the argumentation process was very engaging and motivating for individual and collective learning. Similar finding is reported by Chin as well (Chin, 2006).

\section{Conclusion}

The study aimed at developing and incorporating an approach for introducing argumentation in teaching bio-ethic topics. The researchers developed ILAF consisting of nine steps. The approach was 
experimented with bio-ethic students extended over a semester. The findings revealed the effectiveness of ILAF in developing argumentation skills in students as well as improving the academic performance of students in the final assessment of the bio-ethic course. However, there were some limitations of the study.

The argumentation reports written by students were marked assuming that, it was achievement of individual students. However, the students worked in groups and, therefore, it may have improved the quality of written argumentation reports of the group members. Meanwhile, there were instances when the process of argumentation seemed confrontational even within groups as the students stuck to their claims and were not showing flexibility to abandon their conflicting views (Berland \& Lee, 2012) resulting in wastage of time (Karunatillake \& Jennings, 2004).

Nonetheless, the approach described here is highly relevant in Pakistan where almost total reliance is placed in information transfer by means of lectures. Thus, the teacher training institutes and medical professionals shall take the responsibility of providing training opportunities in argumentation and dialogic learning (Braund, Scholtz, Sadeck, \& Koopman, 2013) as teacher education seriously lacks research related to argumentation(Simon \& Johnson, 2008). Overall, the approach shows considerable promise and has the potential to make contribution in enriching learning and instruction in Pakistan and other developing countries at higher education level.

\section{Recommendations}

The performance data was derived from traditional examinations. These tended to reflect correct recall or recognition of information. There is a further need to develop assessment procedures which explore student conceptual understandings to see if the argumentation approaches brought benefit there as well.

Involvement in argumentation process requires prior knowledge. It is suggested that the teacher should give some kind of reading assignment to students before involving them in argumentation. This would help in more interactive argumentative session with the students.

\section{Acknowledgements}

The researchers acknowledge the useful comments made by Emeritus Professor Dr. Norman Reid of University of Glasgow on an earlier draft of this paper. 


\section{References}

Aydeniz, M., Pabuccu, A., Cetin, P., \& Kaya, E. (2012). Argumentation and students' conceptual understanding of properties and behaviors of gases. International Journal of Science and Mathematics Education, 10(6), 1303-1324.

Berland, L., \& Lee, V. (2012). In pursuit of consensus: disagreement and legitimization during small-group argumentation. International Journal of Science Education,34(12), 1857-1882.

Braund, M., Scholtz, Z., Sadeck, M., \& Koopman, R. (2013). First steps in teaching argumentation: A South African study. International Journal of Educational Development, 33(2), 175-184. https://doi. org/10.1016/j.ijedudev.2012.03.007

Chin, C. A. (2006). Learning to argue. In A. M. O'Donnell, C. E. Silver, \& G. Erkens (Eds.), Collaborative learning, reasoning, and technology (pp. 355-383). Mahwah, NJ: Erlbaum.

Christenson, N., \& Chang, R. S.-N. (2015). A Framework for Teachers' Assessment of Socio-scientific Argumentation: An example using the GMO issue. Journal of Biological Education, 49(2), 204-212. https://doi.org/10.1080/00219266.2014.923486

Dewey, J. (1938). Experience and education. New York: Simon \& Schuster.

Erduran, S., Simon, S., \& Osborne, J. (2004). Taping into argumentation: Developments in the use of Toulmin's argument pattern in studying science discourse. Science Education, 88(6), 915-933.

Faize, F. A. (2011). Problem and prospect of science education at secondary level in Pakistan (Unpublished doctoral dissertation). International Islamic University Islamabad, Pakistan.

Faize, F. A. (2015). Introducing Argumentation at Higher Education in Pakistan Paradigm of Teaching Ethic based Topics. FWU Journal of Social Sciences, 9(1), 8-13.

Faize, F. A., Dahar, M. A., \& Niwaz, A. (2010). Improving Students Performance on Multiple-Choice Questions in Physics- Practice in Justifying the Options. International Journal of Academic Research, 2(6), 204-207. 
Foong, C., \& Daniel, E. (2013). Students' argumentation skills across two socio-scientific issues in a Confucian classroom: Is transfer possible? International Journal of Science Education, 35(14), 2331-2355.

Hong, Z.-R., Lin, H., Wang, H.-H., Chen, H.-T., \& Yang, K.-K. (2013). Promoting and scaffolding elementary school students' attitudes toward science and argumentation through a science and society intervention. International Journal of Science Education, 35(10), 1625-1648.

Iordanou, K. (2013). Developing face-to-face argumentation skills: Does arguing on the computer help? Journal of Cognition and Development, 14(2), 292-320.

Karunatillake, N., \& Jennings, N. (2004). Is it worth arguing? Argumentation in Multi-Agent Systems, 54, 234-250.

Kaya, E. (2013). Argumentation practices in classroom: Pre-service teachers' conceptual understanding of chemical equilibrium. International Journal of Science Education, 35(7), 1139-1158.

Koslowski, B. (1996). Theory and evidence: The development of scientific reasoning. Cambridge: MIT Press.

Lu, J., \& Zhang, Z. (2013). Scaffolding argumentation in intact class: Integrating technology and pedagody. Computer and Education, 69 SRC-, 189-198.

Martin, A., \& Hand, B. (2009). Factors affecting the implementation of argument in the elementary science classroom- A longitudinal case study. Research in Science Education, 39(1), 17-38.

Mascolo, M. F., \& Fischer, K. W. (2004). Constructivist theories. In \& P. R. B. Hopkins, R. G. Barre, G. F. Michel (Ed.), Cambridge encyclopedia of child development. UK: Cambridge University Press.

Newton, P., Driver, R., \& Osborne, J. (1999). The place of argumentation in the pedagogy of school science. International Journal of Science Education, 21(5), 553-576.

Nussbaum, E. M. (2002). Scaffolding argumentation in the social studies classroom. The Social Studies, 93(2), 79-83.

Nussbaum, E. M. (2011). Argumentation, dialogue theory, and 
probability modeling: Alternative framework for argumentation research in education. Educational Psychologists, 46(2), 84-106.

Osborne, J., Christodoulou, A., Howell-Richardson, C., \& Richardson, K. (2013). Learning to argue: A study of four schools and their attempt to develop the use of argumentation as a common instructional practice and its impact on students. Journal of Research in Science Teaching, 50(3), 315-347.

Osborne, J., \& Patterson, A. (2011). Scientific argument and explanation: A necessary distinction. Science Education, 95(4), 627-638.

Piaget, J. (1964). Cognitive development in children: Piaget development and learning. Journal of Research in Science Teaching, 2, 176-186.

Sajjad, S. (2010). Effective teaching methods at higher education level. Pakistan Journal of Special Education, 11, 29-43.

Sampson, V., \& Clark, D. (2008). Assessment of the ways students generate arguments in science education: current perspectives and recommendations for future directions. Science Education, 92, 447-472.

Sampson, V., Grooms, J., \& Walker, J. P. (2011). Argument-driven inquiry as a way to help students learn how to participate in scientific argumentation and craft written arguments: An exploratory study. Science Education, 95(2), 217-257.

Sampson, V., \& Walker, J. (2012). Argument-driven inquiry as a way to help undergraduate students write to learn by learning to write in Chemistry. International Journal of Science Education, 34(10), 1443-1485.

Simon, S., Erduran, S., \& Osborne, J. (2006). Learning to Teach Argumentation: Research and development in the science classroom. International Journal of Science Education, 28(2-3), 235-260. https://doi.org/10.1080/09500690500336957

Simon, S., \& Johnson, S. (2008). Professional learning portfolios for argumentation in school science. International Journal of Science Education, 30(5), 669-688.

Toulmin, S. (1958). The uses of argument. Cambridge, England: Cambridge University Press. 
Umer, S., \& Siddiqui, J. (2013). Improving trends of teaching methods used in the Concept schools of Karachi: an evaluative study. Educational Research International, 2(2), 146-154.

Van Gelder, T., Bissett, M., \& Cumming, G. (2004). Cultivating expertise in informal reasoning. Canadian Journal of Experimental Psychology, 58(2), 142-152.

Von Aufschnaiter, C., Erduran, S., Osborne, J., \& Simon, S. (2008). Arguing to learn and learning to argue: Case studies of how students' argumentation relates to their scientific knowledge. Journal of Research in Science Teaching, 45(1), 101-131.

Vygotsky, L. (1978). Mind in society: The development of higher psychological process. London: Harvard University Press.

Walker, J., \& Sampson, V. (2013). Learning to argue and arguing to learn: argument-driven inquiry as a way to help undergraduate chemistry students learn how to construct arguments and engage in argumentation during a laboratory course. Journal of Research in Science Teaching, 50(5), 561-596.

Yesiloglu, S. N. (2007). Teaching gases topic to high school students through argumentation (Unpublished master's thesis). Ankara: Gazi University.

\section{Citation of this Article:}

Faize, F.A., \& Dahar, M.A. (2017). Developing argumentation skills among undergraduate students using inquiry led argument framework. Pakistan Journal of Education, 34(2), 37-54.

Received on: May $\quad$ 17, 2017

Revised on: November 21, 2017

Accepted on: December 04, 2017 